\title{
Extract from Clarias batrachus Fins as Environmental Benign Corrosion Inhibitor for Mild Steel in Acidic Solution
}

\author{
Shivani Singh ${ }^{1}$, Rahul Singh ${ }^{1, *}$, Neeta Raj Sharma ${ }^{1, *}$, Ambrish Singh ${ }^{2, *}$ \\ ${ }^{1}$ School of Bioengineering and Biosciences, Lovely Professional University, Phagwara, Punjab, India- \\ 144402. \\ ${ }^{2}$ School of New Energy and Materials, Southwest Petroleum University, Chengdu-610500, Sichuan, \\ China. \\ *E-mail:neeta.raj@1pu.co.in; rahul.16188@1pu.co.in; vishisingh4uall@ gmail.com
}

Received: 23 November 2021/ Accepted: 12 January 2022 / Published: 2 February 2022

\begin{abstract}
Extract of Clarias batrachus fins (ECBF) was prepared and detached to solution to prevent mild steel from corroding in $0.5 \mathrm{M}$ sulfuric acid. Gravimetric (weight loss), electrochemical, and exterior characterization experiments were used to investigate the process. As the inhibitor concentration was increased, weight loss tests exposed a boost in inhibition effectiveness and a decrease in corrosion rate. Impedance studies suggested a maximum inhibition efficacy of $95.8 \%$ was achieved with $600 \mathrm{mg} / \mathrm{L}$ of ECBF inhibitor in corrosive media. Electrochemical frequency modulation (EFM) revealed that the casualty factors 2, 3 are consistent with theoretical values, and ECBF is more efficient than blank $(0.5 \mathrm{M}$ $\mathrm{H}_{2} \mathrm{SO}_{4}$ ). The polarization data revealed that the ECBF inhibitor was predominantly cathodic. The ECBF layer generation on the steel surface was discovered using scanning electron microscopy (SEM) and atomic force microscopy (AFM).
\end{abstract}

Keywords: Mild steel; Clarias batrachus; Electrochemical; Corrosion; EFM; AFM

\section{FULL TEXT}

(C) 2022 The Authors. Published by ESG (www.electrochemsci.org). This article is an open access article distributed under the terms and conditions of the Creative Commons Attribution license (http://creativecommons.org/licenses/by/4.0/). 